\title{
THE IMPACT OF FOREIGN DIRECT INVESTMENT ON THE ROMANIAN LABOUR MARKET: NEW EVIDENCE FROM A POOLED MODEL
}

\author{
Laura DIACONU (MAXIM) ${ }^{1}$, Daniel STERBULEAC²
}

DOI: 10.1515/tjeb-2017-0002

\begin{abstract}
The present paper presents a series of results concerning the labour market impact of the foreign direct investment (FDI) inflows in Romania, during the period 2005-2014. In order to reach this objective, we have conducted both an investigation of the specialized literature and an econometric analysis, based on a pooled OLS regression. The added value of this study results from the novelty aspects brought by the results, which indicate two new roles of FDI on the Romanian labour market: a potential "gap-widening" effect between the civil employment and number of employees and a "crawling" effect on the net income. Since the results showed a positive correlation between FDI and civil employment and also between FDI and the average number of employees, the first effect suggests that most of employees of the foreign firms work there less than one year. This may explain why foreign companies are not motivated to offer their employees much higher wages than the local firms and thus that the effect of FDI on nominal net income is very small (“crawling" effect).
\end{abstract}

\section{Keywords: $\quad$ Foreign direct investment; Labour market; Number of employees; Income; Small and medium enterprises; Romania}

\section{JEL Classification: 019; E24}

\footnotetext{
${ }^{1}$ Associate Professor PhD, "Alexandru loan Cuza" University of Iasi, Romania,

2 PhD Student, "Alexandru loan Cuza" University of Iasi, Romania.
} 
Diaconu (Maxim), L., \& Sterbuleac, D. (2017).

The impact of foreign direct investment on the Romanian labour market: new evidence from a pooled model

\section{Introduction}

The increase in the foreign direct investment (FDI) inflows into emerging and developing economies has given rise to a consistent literature that analysed the various impacts of FDI on the host economies. While most of the economists have focused on the direct consequences on the host markets, such as technology transfer, increase in income and employment, raise in government's revenues due to the paid taxes, some other analysts have investigated their indirect effects on local firms, labour force and consumers. In this last category of consequences, the most cited are the increase in competition, in work productivity and efficiency, in quality and quantity of goods and services.

The purpose of the present paper is to analyse the influence of the FDI inflows on the Romanian labour market, during the period 2005-2014. The novelty of this paper results from the fact that the analysis of this impact was regarded from the point of view of three parameters: the number of local employees of the host country, on the net income and on the number of the small and medium enterprises (SMEs). Considering the great importance of the three aspects for the future economic growth of a developing state, as it is Romania, the results may have a significant contribution to the existing literature. It is well known that the higher the employment rate in a country is, the higher the population's well-being is. However, employment brings benefits not only to individuals (microeconomic level), but also to the entire economy of a country (macroeconomic perspective): a higher workforce can lead to an increase in the output and, consequently, in the gross domestic product (GDP). In other words, an employed person has an income, therefore a higher living standard compared to an unemployed individual, he has also the recognition of the peers and the society gets more goods and services. Therefore, we can argue that job creation brings real, tangible, direct and indirect economic and social benefits not only for those employed, but also for all the members of the society.

A higher net income also leads to a higher well-being level. Having more money, people will afford more and better goods and services. Meanwhile, a higher income will allow people improve their health status and education, thus becoming more productive. Therefore, the consequences of higher incomes will be both at microeconomic and at macroeconomic level.

Taking into account the important role the SMEs play in some emerging and developing economies, in terms of employment and contribution to the output, it is necessary to understand the consequences of FDI inflows on them. Moreover, these aspects are important to be identified especially in the context of the aftermath of the global financial crisis, when the traditional financing channels available to SMEs have been limited.

DE GRUYTER OPEN
Timisoara Journal of Economics and Business | ISSN: 2286-0991 | www.tjeb.ro Year 2017 | Volume 10 | Issue 1 | Pages: 19-34 
Diaconu (Maxim), L., \& Sterbuleac, D. (2017).

The impact of foreign direct investment on the Romanian labour market: new evidence from a pooled model

Considering all these aspects, the present paper includes several major parts. In the next section we have conducted a brief literature review, followed by the research hypotheses, after which we present the methodology which helped us develop the fourth part: "Results and discussions". Based on all these aspects, in the last section of the paper we present our conclusions.

\section{Literature review and hypotheses development}

In the specialized literature, one of the most cited effects of FDI inflows is its ability to influence the host country's unemployment rate. This effect is beneficial if the net jobs' gain is positive. The FDI inflows impact on workforce is highly influenced by the foreign companies' entry mode on a market: either through brownfield investments, which usually lead to short term unemployment, or through greenfield investments which generate new workplaces (Matei, 2004). According to lacovoiu (2009), workplaces' losses due to privatization of local firms is not considered a significant disadvantage when privatized companies benefit from foreign capital and they are restructured, thus leading to an efficiency gain. Moreover, due to the spillover effects, they could generate new workplaces. Yet, Ernst (2005) shows that the high inflows of FDI in Argentina, Brazil and Mexico had minimal positive contribution, even negative, sometimes, to the reduction of unemployment in these countries. He assumes that the main cause of this effect is the entry type, as most FDI was not made in new productive activities. Another research also demonstrates that FDI attracted by the Caribbean states did lead to an increase in the unemployment rate (Craigwell, 2006).

Apart from these studies that underline the non-existent or even negative impact of FDI inflows on the employment, most of the analysts consider that FDI has positive effects on the number of jobs of the host economy. In an empirical study conducted in Czech Republic between 1997 and 2004, Bezila (2007) found out that the multinational companies that entered this country succeeded to create efficient jobs' opportunities, to reallocate the resources from the lesser to higher productive activities and, thus, to enhance the total employment. However, when multinationals entered the Czech market, the foreign job creation was accompanied by one third of domestic job destruction. Yet, during the entire analysed period, the displacement effect has significantly been reduced by the new jobs' creation. Similar results of FDI's impact on employment have been found in the case of 48 Sub-Saharan African countries, analysed during the period 1991-2011 (Mayom, 2015). In his study, Mayom (2015) concludes that increasing the FDI inflows in the Sub-Saharan African countries is associated with an increase in the employment ratio.

Other analysts consider that the impact of FDI inflows on the host country's employment rate depends on the fields towards which the investments are directed. More precisely, Lall (1995) argues that FDI leads to higher employment level if the countries direct the FDI to certain

\section{DE GRUYTER OPEN}

Timisoara Journal of Economics and Business | ISSN: 2286-0991 | www.tjeb.ro Year 2017 | Volume 10 | Issue 1 | Pages: 19-34 
Diaconu (Maxim), L., \& Sterbuleac, D. (2017).

The impact of foreign direct investment on the Romanian labour market: new evidence from a pooled model

industries, based on their labour needs. The idea was subsequently developed by Karlsson et al. (2009), who conducted a study on the multinationals' manufacturing subsidiaries from China, between 1998 and 2004. The conclusions of his study reveal that the FDI can positively influence the emergence of new jobs in the analysed Chinese industry.

Apart from these direct effects of FDI on the number of jobs in the host economy, FDI could also have an indirect influence on the country's unemployment rate, through the spillover effects, as foreign firms can create linkages with local suppliers or subcontractors, which, in turn, generate new workplaces. In Ireland, the linkages with local firms were stronger between newly founded companies and other local ones than between foreign companies and local ones, but the differences were not significant (McAleese \& McDonald, 1978). However, in Vietnam, investing firms had the tendency to import most of their necessary goods, therefore creating fewer linkages with local companies (Jenkins, 2006).

The literature regarding the impact of the FDI inflows on the employment in Romania is, unfortunately, quite limited. Most of the studies conducted on Central and Eastern European states, in general, and on Romania, in particular, were focused on the influence of the employment rate in attracting FDI inflows (Hilber \& Voicu, 2009). However, a research conducted by Misztal (2010) shows that the FDI inflows represented a key factor with a significant positive impact on the GDP in Romania between 2000 and 2009, the largest influence on GDP growth being on the employment rate's changes. Taking into account these aspects, we do consider that an analysis of the impact of FDI inflows on the employment level in Romania could underline valuable results. Analysing the relationship between FDI inflows and employment in the host country, we have formulated the first hypothesis:

H1: In Romania, the FDI inflows have a positive impact on the employment level.

The literature often shows that FDI has a strong and positive effect on the net income of local workers in the developing countries. This effect can be analysed from two points of view. Firstly, it is considered that the foreign companies offer significant larger wages to their employees due to the fact that they usually invest in technology-intensive fields, having a higher overall productivity compared with the local companies (Matei, 2004). In this context, they prefer paying more their employees than frequently investing in the training programs, if their labour force would permanently change. An example is brought by Bircan (2013), who studied the situation of some manufacturing plants from Turkey. He argues that the nonproduction workers from multinational companies are the main beneficiaries of the so-called "wage premium". Meanwhile the production workers seem not to benefit of an increased wage. Another reason why the foreign companies offer higher salaries is that they want to limit the technology spillovers (Fosfuri, Motta \& Ronde, 2001), as a compensation for a higher demanding work, relative to the one necessary in local firms (Fabri, Haskel \& Slaughter, 2003). Many studies confirm this aspect, but caution has to be taken since foreign companies usually invest in fields where, in general, wages are higher (Lipsey, 2004). For example, Te

\section{DE GRUYTER OPEN}

Timisoara Journal of Economics and Business | ISSN: 2286-0991 | www.tjeb.ro Year 2017 | Volume 10 | Issue 1 | Pages: 19-34 
Diaconu (Maxim), L., \& Sterbuleac, D. (2017).

The impact of foreign direct investment on the Romanian labour market: new evidence from a pooled model

Velde and Morrisey (2001) show that, in African countries, wages paid by investing companies in production sector are $20-37 \%$ higher than those paid in similar local companies, but when the authors included adjustments specific to foreign firms, such as size, skill mix and capital intensity, the difference drops between $8-23 \%$. This is similar to the findings of Haddad and Harrison (1993) which show that, in Morocco, salaries were $70 \%$ larger in investing firms, but adjusting according to company's particular aspects, this difference drops to $30 \%$. Blomström and Persson (1983) underline that, in Mexico, foreign firms pay salaries 25-30\% higher than those offered by local firms, with the exception of the companies that produce capital goods, where the difference is much smaller. This result was partly confirmed by Feenstra and Hanson (1997). Other studies have showed similar results in Poland (Bedi \& Cielik, 2002) and Indonesia (Hill, 1990; Manning, 1998). Although these studies show that foreign firms do indeed pay higher salaries than the local ones, we agree with Lipsey's (2004) opinion, according to which this result is not very reliable since many studies do not take into account whether the employees of foreign companies have higher income expectations and the fact that the foreign companies may "steal" workers from local firms and thus the mean wage could be unmodified.

Secondly, the wages in a developing country could be raised by the FDI through their positive spillover effects on the productivity of the domestic firms. If the productivity increases, the wages in the local firms could also increase. Aitken et al. (1996) have analysed this relationship between FDI spillover effects and the wages in Mexico, Venezuela and the United States, between 1977 and 1990. Their conclusions show that for both skilled and unskilled workers, a higher share of FDI raises the wage level in both foreign and local firms. Actually, their results suggest that a $10 \%$ increase in the share of foreign investment in the overall employment of a region leads to a $2.2 \%$ increase in wages. Considering that the foreign firms usually invest in highly productive fields which require qualified workers, as previously argued, Gopinath and Chen (2003) have investigated the impact of FDI on host country's wages, taking into account the knowledge endowment factor. They concluded that the FDI inflows increase the wage level only of the skilled labor, both in developed and developing countries. Analysing the positive spillover effects of FDI on host country's wages, other studies have taken into account the positions occupied by the employees in the local firms. For example, a research conducted by Lipsey and Sjöholm (2003) in Indonesia shows that, in all examined cases, positive wage spillover occurred, especially for the local managers. All these aspects may raise the concern that the FDI inflows will increase the income inequalities in the host economy. This issue was addressed by Herzer and Nunnenkamp (2011), in a study on 10 European countries, analysed during the period 1980 to 2000. Their conclusions show that, while FDI has a positive short-run effect on income inequality in Europe, on the long-run the effect is, on average, negative, meaning that an increase in FDI reduces income inequality.

As in the case of the employment, the literature regarding the impact of FDI inflows on the wages' level in Romania is also limited. Most of the studies have focused on the impact of

\section{DE GRUYTER OPEN}


Diaconu (Maxim), L., \& Sterbuleac, D. (2017).

The impact of foreign direct investment on the Romanian labour market: new evidence from a pooled model

the wage levels in attracting the foreign investors in Central and Eastern-European states (Bellak, Leibrecht \& Riedl, 2008) and in Romania (Birsan \& Buiga, 2008). Therefore, analysing of the consequences of the FDI inflows on the wages' level in Romania pays a particular importance for the literature.

Considering the aspects mentioned din the specialized literature regarding the impact of FDI inflows on various host country's wages, we may state the second hypothesis:

H2: There is a positive linkage between FDI inflows and the wages' level in Romania.

A third significant aspect on which we focus our analysis is the impact of FDI inflows on the number of the SMEs from the host country. Unfortunately, the specialised literature does not offer a consistent theoretical background regarding this impact and studies on Romania are almost inexistent on this topic. Most of the analysts have underlined the general consequences of FDI on the total number of companies of a country or on the spillover effects of FDI on firms of various sizes. In this context, it is considered that the tight linkages between the foreign companies and the local ones can lead to an overall increase in the number of local companies, generating afterwards a reduction of unemployment rate. Generally, this is a result of the fact that the foreign companies establish upstream and downstream linkages with local firms. Actually, Dunning (1992) has identified five main types of linkage and spillover effects, by which the presence of multinational companies can positively influence the development of businesses in the host economy: the backward linkages with suppliers, forward linkages with customers, linkages with competitors, with technology partners and other spillover effects. An example that supports the idea of linkages between foreign firms and local partners is brought by Blomström and Persson (1983) and Kokko (1994) who have found statistically significant positive effects of the presence of multinational companies on the Mexican suppliers and distributors. Malaysia is another positive example of country in which linkages between multinational companies and local firms were created. Actually, in this case, there were linkages between multinational semi-conductor plants and local SMEs, established in the late 1980s, as the technological change and the shortening product life cycles encouraged the first ones to delegate more responsibility to the domestic suppliers (Altenburg, 2000). The result was the development of the local supply base offered by SMEs. Similar conclusions were drawn by Smallbone (2006) who states that one of the factors which led to the raise in the number of SMEs in Bulgaria over the last 30 years has been the increase in the outsourcing activities of the multinational companies. Another example is offered by Soo Kim and Leblebicioglu (2016) on the case of South Korea. Actually, they estimate that a 2 percentage point increase in the presence of multinational firms raises the domestic suppliers' investment rate by 2.29 percentage points. The positive inter-industry spillovers that can occur through the linkages between the foreign companies and the suppliers in a country are also confirmed by Gerschewski (2013). However, he considers that the intraindustry productivity spillover effects are negative. This may be explained by the fact that foreign firms reduce the local competitors that are not able to compete against them because

\section{DE GRUYTER OPEN}


Diaconu (Maxim), L., \& Sterbuleac, D. (2017).

The impact of foreign direct investment on the Romanian labour market: new evidence from a pooled model

the local companies may not be able to assimilate and absorb knowledge of multinational companies.

Other authors, such as Ayanwale (2007), consider that the technological spillover effects from the foreign companies to the host economy's firms do occur and they even increase the productivity and efficiency of the local enterprises. In Dutse's (2008) opinion, FDI facilitates productivity of a host developing economy by generating positive spillover effects to local companies, by encouraging innovation in the small and medium size enterprises, by allowing technology adoption and by developing human capital. A clear impact of the FDI on the local SMEs is presented by Ayanwale and Bamire (2001). The results of their study show that the spillover effects of the foreign companies on domestic firms' productivity occur especially in the case of the local SMEs. An opposite conclusion has been drawn by Subair and Salihu (2011), on the case of Nigeria, where the FDI has negatively influenced the development of the SMEs. This result has been attributed to low profit expectations from SMEs and, perhaps, to the fact that the foreign firms entering Nigeria were more risk averse since many of them preferred to import, to purchase from other multinational companies' subsidiaries, or produce in-house rather than investing in the development of linkages with local SMEs.

In the case of India, a report of the Ministry of Overseas Indian Affairs, released in December 2012, reveals the fact that the government encourages the entrance, through FDI, of those multinational companies that will take at least $30 \%$ of their inputs from the local SMEs. The purpose of this measure is, obviously, to develop the domestic SMEs, by offering them the access to supplementary capital and technologies, to global managerial practices and the opportunity for integration into global markets. Smallbone (2006) actually noticed the importance of a policy that would encourage the development of linkages between the foreign companies which entered through FDI in the developing countries and the local SMEs. He considers that such a policy would strengthen and diversify the developing country's SMEs sector and would contribute to poverty alleviation.

Considering all the aspects mentioned above, the third hypothesis of our research is:

H3: In Romania, there is a positive impact of FDI inflows on the number of SMEs.

\section{Research methodology}

\subsection{Variables}

In order to evaluate the causal relationship between FDI inflows and various labour market parameters, six indicators were selected for the analysis. These are the FDI inflows expressed in million Euros, FDlit, the number of active small and medium enterprises SMEit, civil employment CEit in thousands of workers, average number of employees ANEit in thousands,

\section{DE GRUYTER OPEN}

Timisoara Journal of Economics and Business | ISSN: 2286-0991 | www.tjeb.ro Year 2017 | Volume 10 | Issue 1 | Pages: 19-34 
Diaconu (Maxim), L., \& Sterbuleac, D. (2017).

The impact of foreign direct investment on the Romanian labour market: new evidence from a pooled model

the nominal net income Nlit expressed in Romanian RON and an amplified vacancy rate VRit. Each one of the included variables has a time intercept, termed $t$, in our analysis representing the value in a specific year, $t=5 . .14$, and a field intercept, $i$, for each one of the seven fields included in the analysis, $i=1 . .7$. Therefore, the variables used in our study comprise a single transversal area, which can be defined as having $\mathrm{Ni}=7$ fields, namely Mining and quarrying, Manufacturing, Electricity, gas, steam and air conditioning, Construction, Wholesale and retail, Hotels and restaurants and Transport.

At this point, it is important to mention that our analysis relies on a heterogeneous group of work-fields which experienced different transformations during the analysed period. It could be stated that this may lead to a dataset that includes divergent parameters. In order to minimize the heteroscedasticity of our dataset, we performed a Box-Cox transformation using an arbitrary lambda constant of 0.5 . Therefore, all retrieved values were redefined using the formula: new value $=\left(\right.$ old_value $\left.{ }^{\wedge} 0.5-1\right) / 0.5$.

Some specifications should be made regarding the differences between the civil employment and the average number of employees. According to the National Institute of Statistics (2012), while the civil employment represents the number of persons who carried out a paid activity for at least one hour during the reference year, excepting military staff and similar, the average number of employees is an arithmetic mean resulted from the sum of the daily employee's number divided to the total calendar days of the year. Therefore, the average number of employees is an indicator which describes better the total working capacity of a country, but the civil employment, with its much larger values, shows exactly how many people have worked, even if occasionally. In fact, since the 1990's, the ratio between average number of employees and civil employment dropped constantly. While the early 1990's were marked by a ratio of about $80 \%$, in the beginning of 2000 's the ratio was around $60 \%$ and in the early 2010's the ratio dropped only to about $50 \%$. One explanation for these differences could be the fact that in the 1990s the share of the people working full time or all year round was higher than nowadays. Nevertheless, the values are prone to autocorrelation and will be included separately in our models.

All data except the FDI inflows was retrieved from the National Institute of Statistics Website, specifically from the Romanian Statistical Yearbooks, from 2006 to 2011 (National Institute of Statistics, 2012) and from the Romania in Numbers 2012-2015 publication (National Institute of Statistics, 2016). The data for the FDI inflows was retrieved from the Foreign Direct Investment in Romania in 2006-2014 publication (National Bank of Romania, 2015). The 7 fields selected and previously indicated were the only ones commonly reported by both publications.

DE GRUYTER OPEN
Timisoara Journal of Economics and Business | ISSN: 2286-0991 | www.tjeb.ro Year 2017 | Volume 10 | Issue 1 | Pages: 19-34 
Diaconu (Maxim), L., \& Sterbuleac, D. (2017).

The impact of foreign direct investment on the Romanian labour market: new evidence from a pooled model

\subsection{Models}

Although the data we use seems suited for a panel data analysis and could be regressed through a panel data specific model, we chose not to do so as the number of intercepts is too small to yield better results than a simple ordinary least squares (OLS) regression. Therefore, our analysis does not take into account the specific individuality between fields, thus representing a pooled OLS regression. Because some data was missing from the National Institute of Statistics (2016), namely the 2014 values for the average number of employees and the number of active small and medium enterprises, two versions of the model were included, Version one (V1) with all 6 indicators, including only years 2005-2013, and Version two (V2), in which only 4 out of 6 indicators were used (apart from SMEit and ANEit) but this includes all years that are currently and publicly reported, 2005-2014. Such distinction also allowed us to compare the results and to observe whether an effect in one version has the same capacity in the other version. Therefore, $\mathrm{Nt}=10$ in $\mathrm{V} 1$ and $\mathrm{Nt}=9$ in $\mathrm{V} 2$. The models can be written as

$$
\begin{gathered}
d e p=\beta_{0}+\beta_{1} F D I_{i=1 . .7, t=5.13}+\beta_{2} x_{i=1 . .7, t=5.13}+\beta_{3} y_{i=1 . .7, t=5.13}+\beta_{4} z_{i=1 . .7, t=5 . .13}+\epsilon \\
\operatorname{dep}=\beta_{0}+\beta_{1} F D I_{i=1 . .7, t=5.14}+\beta_{2} x_{i=1.7, t=5.14}+\beta_{3} y_{i=1.7, t=5.14}+\epsilon
\end{gathered}
$$

using the standard statistical notations for the coefficients.

Additionally, in order to identify the FDI effects on the CE and ANE, V1 includes two different regression sets, one which excludes ANE and another which excludes $C E$. As such, each set of V1 includes 4 different independent regression equations while V2 includes 3 different independent regression equations. Each of the included variables took turn to becoming an independent variable, therefore, in $\mathrm{V} 1$ the dependent variable (dep) was, one by one, either $\mathrm{CE}, \mathrm{VR}, \mathrm{NE}$ and SME, while the other three variables were $\mathrm{x}, \mathrm{y}$ and $\mathrm{z}$ in our model. The other set of V1 used ANE instead of CE. Conversely, in V2, the variables CE, VR and NI took turns to becoming a dependent variable, while the other two were modelled as independent variables. This allowed us to observe all possible causal relationships between the selected indicators, making our research a thorough one. All calculations were performed using $\mathrm{R}$. Here, we may state that we deal with a divergent dataset that comprises data from some work-fields that are very different one from the other. Our dataset does include some outliers, which may exert their effects even after the Box-Cox transformation, rendering our regression sensitive to validation tests. Nevertheless, in order to check for heteroscedasticity among our models, we performed the Breusch-Pagan test (BP-test) whose null hypothesis assumes homoscedasticity.

\section{DE GRUYTER OPEN}

Timisoara Journal of Economics and Business | ISSN: 2286-0991 | www.tjeb.ro Year 2017 | Volume 10 | Issue 1 | Pages: 19-34 
Diaconu (Maxim), L., \& Sterbuleac, D. (2017).

The impact of foreign direct investment on the Romanian labour market: new evidence from a pooled model

\section{Results and discussions}

The following tables show the results obtained through the pooled OLS regression for both versions involved. As previously stated, each of the variables used in our study took turns to being a dependent variable, except FDI, as such generating different equations in Version 1 , which has two sets of models, one excluding ANE (Table 1) and another excluding CE (Table 2) and in the second Version (Table 3).

Table 1. Results of the ANE-excluding pooled OLS of V1 of the econometric model

\begin{tabular}{|c|c|c|c|c|}
\hline & \multicolumn{4}{|c|}{ DEPENDENT VARIABLES } \\
\hline & CE & VR & $\mathrm{NI}$ & SME \\
\hline \multirow[t]{2}{*}{ CE } & & $0.166 * * *$ & $-0.457 * * *$ & $11.013 * * *$ \\
\hline & & {$[0.054]$} & [0.148] & [2.657] \\
\hline \multirow[t]{2}{*}{ VR } & $0.856 * * *$ & & $-1.243 * * *$ & $-15.442 * *$ \\
\hline & {$[0.276]$} & & [0.323] & [6.559] \\
\hline \multirow[t]{2}{*}{$\mathrm{NI}$} & $-0.310 * * *$ & $-0.164 * * *$ & & -3.708 \\
\hline & {$[0.100]$} & {$[0.043]$} & & {$[2.444]$} \\
\hline \multirow[t]{2}{*}{ SME } & $0.021 * * *$ & $-0.006 * *$ & -0.01 & \\
\hline & [0.005] & {$[0.002]$} & {$[0.007]$} & \\
\hline \multirow[t]{2}{*}{ FDI } & $0.216 * * *$ & -0.008 & $0.175 * * *$ & $-1.401 *$ \\
\hline & {$[0.019]$} & [0.015] & [0.035] & {$[0.766]$} \\
\hline \multirow[t]{2}{*}{ (Intercept) } & $22.573 * *$ & $19.693 * * *$ & $89.569 * * *$ & $493.628 * *$ \\
\hline & {$[9.674]$} & [3.633] & [3.544] & [223.937] \\
\hline R-squared & 0.868 & 0.621 & 0.67 & 0.469 \\
\hline BP-test & $p>0.05$ & $p<0.05$ & $p>0.05$ & $p<0.05$ \\
\hline
\end{tabular}

Standard errors in square brackets, independent variables are placed in the left column, ${ }^{*}$ denotes significance at the following levels: $* * * p<0.01, * * p<0.05, * p<0.1$

Table 2. Results of the CE-excluding pooled OLS of V1 of the econometric model

\begin{tabular}{|c|c|c|c|c|}
\hline & \multicolumn{4}{|c|}{ DEPENDENT VARIABLES } \\
\hline & ANE & VR & $\mathrm{NI}$ & SME \\
\hline \multirow[t]{2}{*}{ FDI } & $0.176 * * *$ & -0.008 & $0.167 * * *$ & -1.165 \\
\hline & {$[0.016]$} & [0.014] & {$[0.034]$} & {$[0.760]$} \\
\hline \multirow[t]{2}{*}{ ANE } & & $0.200 * * *$ & $-0.505 * * *$ & $12.369 * * *$ \\
\hline & & {$[0.062]$} & {$[0.177]$} & [3.214] \\
\hline \multirow[t]{2}{*}{ VR } & $0.758 * * *$ & & $-1.286 * * *$ & $-15.580 * *$ \\
\hline & {$[0.236]$} & & {$[0.326]$} & [6.708] \\
\hline $\mathrm{NI}$ & $-0.245 * * *$ & $-0.164 * * *$ & & $-4.329 *$ \\
\hline
\end{tabular}

DE GRUYTER OPEN 
Diaconu (Maxim), L., \& Sterbuleac, D. (2017).

The impact of foreign direct investment on the Romanian labour market: new evidence from a pooled model

\begin{tabular}{ccccc}
\hline \multicolumn{1}{c}{$[0.086]$} & {$[0.042]$} & & {$[2.441]$} \\
\hline SME & $0.016 * * *$ & $-0.005 * *$ & $-0.012 *$ & \\
\hline Intercept) & $16.996 * *$ & $19.804 * * *$ & $89.517 * * *$ & $556.125 * *$ \\
\hline & {$[8.258]$} & {$[3.541]$} & {$[3.603]$} & {$[222.969]$} \\
\hline R-squared & 0.859 & 0.625 & 0.663 & 0.452 \\
\hline BP-test & $p>0.05$ & $p<0.05$ & $p>0.05$ & $p<0.05$ \\
\hline
\end{tabular}

Standard errors in square brackets, independent variables are placed in the left column, ${ }^{*}$ denotes significance at the following levels: $* * * p<0.01, * * p<0.05, * p<0.1$

Table 3. Results of the pooled OLS of V2 of the econometric model

\begin{tabular}{|c|c|c|c|}
\hline & \multicolumn{3}{|c|}{ DEPENDENT VARIABLES } \\
\hline & CE & VR & $\mathrm{NI}$ \\
\hline \multirow[t]{2}{*}{ CE } & & $0.128 * * *$ & $-0.646 * * *$ \\
\hline & & {$[0.048]$} & {$[0.114]$} \\
\hline \multirow[t]{2}{*}{ FDI } & $0.237 * * *$ & -0.003 & $0.209 * * *$ \\
\hline & [0.019] & {$[0.014]$} & [0.030] \\
\hline \multirow[t]{2}{*}{ VR } & $0.757 * * *$ & & $-1.016 * * *$ \\
\hline & [0.285] & & [0.316] \\
\hline \multirow[t]{2}{*}{$\mathrm{NI}$} & $-0.504 * * *$ & $-0.134 * * *$ & \\
\hline & [0.089] & [0.041] & \\
\hline \multirow[t]{2}{*}{ (Intercept) } & $42.594 * * *$ & $16.607 * * *$ & $87.913 * * *$ \\
\hline & [8.505] & [3.558] & {$[3.304]$} \\
\hline R-squared & 0.833 & 0.577 & 0.66 \\
\hline BP-test & $p>0.05$ & $p<0.05$ & $p>0.05$ \\
\hline
\end{tabular}

Standard errors in square brackets, independent variables are placed in the left column, *denotes significance at the following levels: $* \star * p<0.01, * \star p<0.05, * p<0.1$

The results of the two versions clearly indicate that FDI has multiple effects on some of the 5 indicators selected for analysis. The BP-test clearly rules out several models from the analyses, including the effects on vacancy rate and the number of small and medium enterprises. There is a positive and significant correlation between FDI inflows and civil employment and average number of employees, however, to different extents. It is known that there is currently a gap-widening effect between the civil employment and the average number of employees in Romania. Our analysis shows that FDI inflows were unable to diminish this gap. This could have been clarified by the effect of FDI on vacancies rate, but such a model should be repeated in further research. This correlation between FDI and the average number of employees, on one hand, and between FDI and the civil employment, on the other hand, could be explained by the fact that most of the employees of the fore ign firms

DE GRUYTER OPEN
Timisoara Journal of Economics and Business | ISSN: 2286-0991 | www.tjeb.ro Year 2017 | Volume 10 | Issue 1 | Pages: 19-34 
Diaconu (Maxim), L., \& Sterbuleac, D. (2017).

that entered the Romanian market either have part-time contracts, or, more likely, work for these companies less than one year, thus providing a preliminary consideration for a hidden "gap-widening" effect exerted by FDI on these two specific parameters. These results are not fully in line with our expectations, which were based especially on the analysis of the case of other countries from the Central and Eastern Europe, such as Czech Republic (Bezila, 2007). Considering these aspects, we only partially accepted the first research hypothesis ( $\mathrm{H} 1)$.

FDI inflows have a significant beneficial effect on the net income, in all tested versions. An increase in FDI inflows of 1 transformed unit should bring an increase in salaries of approximately 0.2 salary units. Holding account of the average FDI inflow and net income in the selected domains, reverse-performing the transformation suggests that an increase in FDI inflows of 70 million Euros should increase the wages in that domain with approximately 38 Romanian RON (nearly 8 Euros). The coefficient values are small and affirm a "crawling" effect of FDI on salaries, which leads to the assumption that foreign investing companies prefer, or have the tendency, to keep the wages they offer to a certain and constant level, which is correlated with the salary level of the local firms. The explanation of this result is related to the one mentioned before, when arguing the partially acceptance of the first research hypothesis. So, if we consider that most of the employees of the foreign firms work for them less than one year, these companies are not motivated to offer them much higher wages than the local firms, as we saw it was the case of Mexico (Aitken et al.,1996), Indonesia (Lipsey \& Sjöholm, 2003), Poland (Bedi \& Cielik, 2002) or some African countries. Moreover, we should add the fact that the foreign firms may have only a reduced positive spillover effect on the local companies, since the effect of FDI on nominal net income is very small. As mentioned in the literature, if FDI would have significant positive spillover effects on the productivity of the domestic firms, the wages in the local firms could also considerably increase. Based on the statistical results, the second research hypothesis (H2) is accepted.

As in the analysis conducted by Subair and Salihu (2011) on the case of Nigeria, in Romania FDI inflows seem to have a negative effect on the number of small and medium enterprises, but the models have to be rejected due to low R-squared values and heteroscedasticity. Further research is needed in order to test this assumption. Nevertheless, it can be stated that FDI inflows in Romania had no effect on the number of small and medium enterprises. However, the explanations for this result are completely different than that for the case of Nigeria, where this consequence has been attributed to low profit expectations from SMEs and, perhaps, to the fact that the foreign firms entering the country were more risk averse. Based on the arguments offered by the specialized literature, we could say that, in Romania, this result may be attributed to the fact that the foreign firms reduce the local competitors because they are not be able to absorb the positive spillover effects generated by the multinational companies. This explanation is related to the previous one, when we mentioned why the effect of FDI on nominal net income is very small. In addition, we may also assume that the foreign firms do not develop many linkages with the local SMEs, as it happens in the

\section{DE GRUYTER OPEN}


Diaconu (Maxim), L., \& Sterbuleac, D. (2017).

The impact of foreign direct investment on the Romanian labour market: new evidence from a pooled model

case of South-Korea (Soo Kim \& Leblebicioglu, 2016), Mexico (Kokko, 1994) or Malaysia (Altenburg, 2000).

Given the statistical result regarding the effect of FDI on SMEs in Romania and the low quality of the data, we have to reject the third research hypothesis $(\mathrm{H} 3)$.

\section{Conclusions}

The added value of the paper results from the three major conclusions that can be drawn from our analysis. First of all, we saw that there is a positive correlation between FDI and civil employment and also between FDI and the average number of employees, even if at a lower extent. Therefore, we have identified a first important aspect: FDI does not seem to positively influence the "gap-widening" effect on these two specific parameters or it is even possible that FDI causes this effect. Secondly, even if FDI has a significant effect on the net income, this is much reduced. We called this impact the "crawling" effect of FDI on salaries. The third main conclusion of our research is that FDI did not influence the number of SMEs.

All these three findings present a great importance at least from two points of view. First of all, since these aspects have not been previously approached on Romania's case, the present study enlarges the literature on this topic. Secondly, the results offer a broader and coherent image of the FDI inflows' impact on the Romanian labour market since the explanations of the three conclusions are related. The fact that most of employees of the foreign firms work there less than one year could be a good explanation of the fact that these companies are not motivated to offer their employees much higher wages than the local firms. Moreover, if we consider that the effect of FDI on nominal net income is very small, we may believe that the foreign companies may have only a reduced positive spillover effect on the local ones. This could also explain the negative impact of FDI on the SMEs which cannot compete with the foreign companies because they are not be able to absorb the positive spillover effects generated by the multinationals. Since the third result can also be a consequence of the fact that foreign firms do not develop many linkages with the local SMEs, it would be advisable that the authorities develop and implement a policy that would foster these linkages. The importance of this policy results from the fact that, in this way, the SMEs sector could strengthen and diversify and, therefore, it could contribute to an increase in the employment and wages.

Considering the results obtained through the statistical analysis, we have entirely accepted only one of the research hypotheses, partly accepted another one and rejected the third hypothesis. These aspects prove, once again, that the effects of FDI can significantly vary among countries due to the high number of the parameters that define the relations between FDI and other indicators.

DE GRUYTER OPEN
Timisoara Journal of Economics and Business | ISSN: 2286-0991 | www.tjeb.ro Year 2017 | Volume 10 | Issue 1 | Pages: 19-34 
Diaconu (Maxim), L., \& Sterbuleac, D. (2017).

\section{References}

Aitken, B., Harrison, A., \& Lipsey, R. (1996). Wages and Foreign Ownership A Comparative Study of Mexico, Venezuela, and the United States. Journal of International Economics, 40(3), 345-371.

Altenburg, T. (2000). Linkages and Spillovers between Transnational Corporations and Small and MediumSized Enterprises in Developing Countries - Opportunities and Policies. Berlin: German Development Institut.

Ayanwale, A. B. (2007). FDI and Economic Growth: Evidence from Nigeria. African Economic Research Consortium Research Paper No. 165.

Ayanwale, A. B., \& A. S. Bamire. (2001). The Influence of FDI on Firm Level Productivity of Nigeria's Agro/Agro-Allied Sector. Final Report Presented to the African Economic Research Consortium, Nairobi.

Bedi, A., S., \& Cielik, A. (2002). Wages and growth in Poland: The role of foreign direct investment, Economics of Transition, 10(1), 1-27.

Bellak, C., Leibrecht, M., \& Riedl, A., (2008). Labour costs and FDI flows into Central and Eastern European countries: a survey of the literature and empirical evidence, Structural Change and Economic Dynamics, 19(1), 17-37.

Bezila, L. (2007). Impact of Foreign Direct Investment on the Labour Market in the Czech Republic and other European Countries. University of Economics, Prague. Retrieved from

https://www.vse.cz/vskp/971_impact_of_foreign_direct_investment_on_the_labo ur_market_in_the_czech_repüblic_and_other_european_countries

Bircan, C. (2013). Foreign direct investment and wages: does the level of ownership matter? European Bank for Reconstruction and Development Working Paper No. 157. Retrieved from http://www.ebrd.com/downloads/research/economics/workingpapers/wp0157.pdf

Birsan, M., \& Buiga, A. (2009). FDI determinants: case of Romania, Transitions Studies Review, 15(4), 726-736.

Blomström, M., \& Persson, H. (1983). Foreign investment and spillover efficiency in an underdeveloped economy: Evidence from the Mexican manufacturing industry. World Development, 11(6), 493-501.

Craigwell, R. (2006). Foreign Direct Investment and Employment in the English and DutchSpeaking Caribbean. Port of Spain: ILO, Retrieved from http://www.ilo.org/wcmsp5/groups/public/---americas/---ro-lima/---sroport_of_spain/documents/meetingdocument/wcms_306245.pdf

Dunning (1992). Multinational Enterprise and the Global Economy. Reading, Mass.: AddisonWesley.

Dutse, A.Y. (2008). Nigeria economic Growth emphasizing the role of foreign Direct investment in transfer of Technology. Communication of IBIMA, 3, 11-16.

Ernst, C. (2005). The FDI-employment link in a globalizing world: The case of Argentina, Brazil and Mexico. ILO Employment Strategy Papers.

Fabri, F., Haskel, J., E. \& Slaughter, M., J. (2003). Does Nationality of Ownership Matter for Labor Demands? Journal of the European Economic Association, Papers and Proceedings, 1(2-3), 698-707.

Feenstra, R. C., \& Hanson, G. H. (1997). Foreign direct investment and relative wages: Evidence from Mexico's maquiladoras. Journal of International Economics, 42(3-4), 371-393. 
Diaconu (Maxim), L., \& Sterbuleac, D. (2017).

The impact of foreign direct investment on the Romanian labour market: new evidence from a pooled model

Fosfuri, A., Motta, M., \& Ronde, T. (2001). Foreign Direct Investments and Spillovers through Workers' Mobility. Journal of International Economics, 53(1), 205-222.

Gerschewski, S. (2013). Do Local Firms Benefit from Foreign Direct Investment? An Analysis of Spillover Effects in Developing Countries. Asian Social Science, 9(4), 67-76.

Gopinath, M., \& Chen, W. (2003). Foreign Direct Investment and Wages: A Cross-Country Analysis. Journal of International Trade \& Economic Development, 12(3), 285-309.

Haddad, M., \& Harrison, A. (1993). Are there positive spillovers from direct foreign investment? Journal of Development Economics, 42(1), 51-74.

Herzer, D., \& Nunnenkamp, P. (2011). FDI and Income Inequality: Evidence from Europe. Kiel Institute for the World Economy, Working Paper No. 1675, Retrieved from https://www.ifw-members.ifw-kiel.de/publications/fdi-and-income-inequalityevidence-from-europe/kwp_1675.pdf

Hilber, C.A., \& Voicu, I. (2009). Agglomeration Economies and the Location of Foreign Direct Investment: Empirical Evidence from Romania. Regional Studies, 44(3), 355-371. Hill, H. (1990). Indonesia's industrial transformations, Part II. Bulletin of Indonesian Economic Studies, 26(3), 75-109.

lacovoiu, V. B. (2009). Investiţiile străine directe între teorie şi practică economică: analize comparative. Bucharest: ASE.

Jenkins, R. (2006). Globalization, FDI and employment in VietNam. Transnational Corporations, 15(1), 115-142.

Karlsson, S., Lundin, N., Sjoholm, F., \& He, P. (2009). Foreign Firms and Chinese Employment. World Economy, 32(1), 178-201.

Kokko, A. (1994). Technology, market characteristics, and spillovers. Journal of Development Economics, 43(2), 279-293.

Lall, S. (1995). Employment and foreign investment: policy options for developing countries. International Labour Review, 134(4-5), 521-540.

Lipsey, E. R. (2004). Home and Host Country Effects of Foreign Direct Investment. In R. E. Baldwin \& L. A. Winters (Eds.), Challenges to Globalization: Analizing the Economics. University of Chicago Press.

Lipsey, E. R. \& Sjöholm, F. (2003). Foreign Firms and Indonesian Manufacturing Wages. NBER Working Paper Series, 9417.

Manning, C. (1998). Indonesian labour in transition: An East Asian success story? Cambridge: Cambridge University Press.

Matei, M. (2004). Investiţiile străine directe - funç̧ii şi evoluţii. Bucharest: Expert.

Mayom, D. A. (2015). The Impact of Foreign Direct Investment on Labor Market Measures: Evidence from Sub-Saharan Africa. The University of san Francisco, Retrieved from http://repository.usfca.edu/cgi/viewcontent.cgi?article=1162\&context=thes

McAleese D., \& McDonald D. (1978). Employment Growth and the Development of Linkages in Foreign-owned and Domestic Manufacturing Enterprises. Oxford Bulletin of Economics and Statistics, 40(4), 321-339.

Ministry of Overseas Indian Affairs (2012). Impact of FDI on SMEs. Press Information Bureau, Government of India, Retrieved from

http://pib.nic.in/newsite/PrintRelease. aspx?relid=90112

Misztal, P. (2010). Foreign Direct Investments as a factor for economic growth in Romania. Review of Economic and Business Studies, III(1), 39-54.

National Bank of Romania (2015). Foreign direct investment in Romania, 2006-2014. Retrieved from http://www.bnr.ro/PublicationDocuments.aspx?icid=14364

DE GRUYTER OPEN 
Diaconu (Maxim), L., \& Sterbuleac, D. (2017).

The impact of foreign direct investment on the Romanian labour market: new evidence from a pooled model

National Institute of Statistics (2012). Romanian Statistical Yearbook, 2006-2011. Retrieved from http://www.insse.ro/cms/ro/content/arhiva-anuare-statistice

National Institute of Statistics (2016). Romania in Numbers, 2012-2015. Retrieved from http://www.insse.ro/cms/ro/content/alte-publicatii

Smallbone, D. (2006). Foreign direct investment and SME development: some policy issues for transition and developing countries. Proceedings of the international conference "Entrepreneurship in the United Europe: Challenges and Opportunities", Sunny Beach, Bulgaria.

Soo Kim, K., \& Leblebicioglu, A. (2016). The Impact of FDI in Vertically Integrated Sectors on Domestic Investment: Firm-level Evidence from South Korea. Working Paper, Retrieved from https://aric.adb.org/pdf/events/aced2016/paper_aslileblebicioglu.pdf

Subair, K., \& Salihu, O. (2011). Foreign direct investment and development of small and medium scale enterprises in Nigeria. African Journal of Accounting, Economics, Finance and Banking Research, 7(7), 64-77.

Te Velde, D. W., \& Morrisey O. (2001). Foreign Ownership and Wages: Evidence from Five African Countries. CREDIT Research Paper No. 01/19, Centre for Research in Economic and International Trade, University of Nottingham. 